J. Phys. Chem. A, 117, 12726-12733 (2013), DOI: 10.1021/jp411044m

This document is the unedited author's version of a Submitted Work that was subsequently accepted for publication in Journal of Physical Chemistry A, copyright (C) American Chemical Society after peer review. To access the final edited and published work, see: http://pubs.acs.org/doi/pdf/10.1021/jp411044m

\title{
Effect of temperature and substitution on Cope rearrangement - A symmetry perspective
}

Inbal Tuvi-Arad ${ }^{\dagger *}$, Tamás Rozgonyi ${ }^{\star}$ and András Stirling $\S^{\text {* }}$

${ }^{\dagger}$ Department of Natural Sciences, The Open University of Israel, 1 University Rd., Raanana 43107, Israel, Tel: 972-9-778-1773, Fax: 972-9-778-0661; E-mail: Inbaltu@openu.ac.il

*Institute of Materials and Environmental Chemistry, Research Center for Natural Sciences of the HAS, Pusztaszeri ut 59-67, Budapest 1025, Hungary

${ }^{\S}$ Institute of Organic Chemistry, Research Center for Natural Sciences of the HAS, Pusztaszeri ut 59-67, Budapest 1025, Hungary, E-mail: stirling.andras@ $@$ ttk.mta.hu 


\begin{abstract}
Many reactions feature symmetry variation along the reaction path on the potential energy surface. The interconversion of the point group symmetry of the stationary points can be characteristic of these processes. Increasing the temperature, however, leads to the loss of symmetry in its traditional yes-no language. We find that in such cases the instantaneous distance of the molecular structure from its symmetric counterpart is a suitable collective variable that can describe the reaction process. We show that this quantity, the continuous symmetry measure (CSM) has a positive linear relationship with temperature, implying that even highly symmetric molecules should be considered as asymmetric above $0 \mathrm{~K}$. Using ab initio molecular dynamics we simulate the temperature induced Cope rearrangements of several fluxional molecules and employ different CSM-s to follow the reaction progress. We use this methodology to demonstrate the validity of important concepts governing these reactions: Woodward-Hoffmann rules and TS aromaticity. Statistical analysis of the CSM distributions reveals that ligands connected to the carbon frame have profound effect on the reaction course. In particular our results show that lower temperatures tend to enhance the differences between the TS-stabilizing effect of the substituents.
\end{abstract}

\title{
KEY WORDS
}

Molecular dynamics, Symmetry measures, Pericyclic reactions, Aromaticity. 


\section{INTRODUCTION}

The study of a concerted reaction at finite temperature requires a reaction coordinate that can distinguish between the reactant, product and transition state (TS) in their distorted geometries. Generally, a reaction coordinate is a single variable that depends on several or all positional degrees of freedom, varies continuously along the reaction path and allows for clear distinction between different stationary points. Typical such variable is the intrinsic reaction coordinate (IRC) ${ }^{1,2}$ which describes the very low temperature mechanism on the potential energy surface (PES). However, when temperature effects become non-negligible other coordinates must be selected in order to account for the thermal fluctuations (the work of Sun et $\mathrm{al}^{3}$ on $\mathrm{S}_{\mathrm{N}} 2$ mechanism and Ammal et $\mathrm{al}^{4}$ on heterolysis rearrangements are illustrative examples). In general, a suitable reaction coordinate has a collective nature and describes all the relevant slow movements involved in the reaction step. Common examples are coordination numbers ${ }^{5}$ and path variables ${ }^{6}$ which have been employed successfully for various problems (see Ref. ${ }^{7}$ and references therein).

Very recently a specific collective variable, the continuous symmetry measure (CSM) ${ }^{8}$ has been invoked to follow reaction progress along the IRC ${ }^{9}$. The CSM methodology expands the language of symmetry from its traditional yes-no nature while combining all the geometrical parameters of a molecular structure into a single global parameter that measures the distance a structure has from its symmetric counterpart. Since its original development, the method has been broadened to measure chirality ${ }^{10-12}$ and shape ${ }^{13-15}$ and applied to a large number of problems ${ }^{16-20}$. Excellent correlations were found between the CSM and various physical and chemical properties ${ }^{21-23}$. In particular, it has been shown 
that the variation of the CSM values along the IRC can serve as an indicator for the progress of a reaction $^{9,24,25}$.

In the present study we applied the CSM as efficient reaction coordinate at finite temperatures and in the absence of perfect symmetry. For this purpose we selected the Cope rearrangement ${ }^{26}$ of several fluxional molecules shown in scheme 1: bullvalene (I) and barbaralane (II) as well as semibullvalene (III, $\mathrm{X}=\mathrm{H}$ ) and its derivatives: 3methylsemibullvalene (III, $\mathrm{X}=\mathrm{Me}$, ); 3-aminosemibullvalene (III, $\mathrm{X}=\mathrm{NH}_{2}$ ) and 2,6diazasemibullvalene (IV), and followed their intramolecular rearrangements at elevated temperatures by ab initio molecular dynamics (AIMD) ${ }^{27}$. The conservation of orbital topology dictated by the Woodward-Hoffmann (WH) rules $^{28,29}$ implies that the rearrangements of these molecules proceed in a concerted fashion. The concertedness can be followed by properly selected CSM-s. We have calculated the temporal variations of suitable CSM variables along the AIMD trajectories. After having found a linear dependence of CSM with temperature we show that CSMs are powerful descriptors to follow the temperature-induced intramolecular Cope reactions of these molecules. In addition our analysis provides new insight about the role of temperature and substitution on the reaction mechanism of semibullvalene derivatives. 
Scheme 1: Cope rearrangements of the selected fluxional molecules. Breaking bonds are marked in red.
I
$\mathrm{I}=\hat{\mathrm{O}}$
III $=x$
IV

\section{COMPUTATIONAL METHODS}

Molecular Dynamics. All AIMD calculations have been performed using the CP2K package $^{30}$. The simulations employed a periodic cubic box of $11 \AA$. The electronic structure calculations were done in the framework of the density functional theory (DFT) using the BLYP functional ${ }^{31,32}$. We have employed the double- $\zeta$ basis sets augmented with one set of polarization functions. Only the valence electrons have been included explicitly into the calculations, while the interaction between the core and valence electrons were accounted for by using Goedecker-Teter-Hutter-type pseudopotentials ${ }^{33}$. The electronic charge density has been expanded by an auxiliary plane-wave set defined by 300 Ry cutoff energy. The simulations have been performed in canonical (NVT) conditions at different temperatures by using a massive Nose-Hoover coupling scheme ${ }^{34}$. The time step to integrate the equations of motion was $0.4 f s$ for semibullvalene and its derivatives and $0.5 f s$ for barbaralane at all temperatures. For bullvalene we selected 0.8 $f_{s}$ for $800 \mathrm{~K}$ and $0.4 f s$ for all the other temperatures $(1200$ and $1800 \mathrm{~K})$. Preliminary tests 
for the studied systems showed that these time steps provide good accuracy relatively to the computational effort.

Ground state calculations. The Gaussian package ${ }^{35}$ was used to characterize the PES, to generate the IRC curves and to calculate Nuclear-Independent Chemical Shifts ${ }^{36,37}$ (NICS) values. The NICS parameters are the absolute magnetic shieldings taken with reversed sign at a selected point. Test calculations showed that NICS values computed at $0.5 \AA$ below the center of the ring formed by the carbon atoms participating in the Cope rearrangements reflect remarkably well the temporal variation of the aromaticity of the molecules ${ }^{38}$. In the present case we calculated the NICS values of the trajectories of barbaralane at randomly selected intervals. The $\mathrm{B} 3 \mathrm{LYP} \mathrm{P}^{31,32,39,40}$ functional was used for the PES exploration (optimizations, TS localization and IRC calculations and NICS along the IRC) with the $6-311+\mathrm{G}^{*}$ basis set. The NICS values along the AIMD trajectories were calculated with a smaller basis set at the B3LYP/6-31+G* level in order to reduce numerical cost. The choice of functional and basis set as well as AIMD parameters have been proven adequate for this type of problems ${ }^{38}$.

Symmetry calculations. The inputs for a CSM calculation are the actual coordinates $\left\{\boldsymbol{Q}_{k}, k=1,2, \ldots, N\right\}$ and the assumed symmetry point group $G$. The algorithm generates a series of structures with the same atoms and vertex labeling as the initial structure but with symmetry $G$. From this series, the selected final symmetric structure with coordinates $\left\{\boldsymbol{P}_{k}, k=1,2, \ldots, N\right\}$ is the one with minimal distance to the original structure as defined by Eq. (1): 


$$
S(G)=100 \times \frac{\sum_{k=1}^{N}\left|\mathbf{Q}_{k}-\mathbf{P}_{k}\right|^{2}}{\sum_{k=1}^{N}\left|\mathbf{Q}_{k}-\mathbf{Q}_{0}\right|^{2}}
$$

Here $\boldsymbol{Q}_{0}$ is the center of mass of the original distorted structure. $S(G)$ in Eq. (1) is called the continuous symmetry measure. The denominator in Eq. (1) is a mean square size normalization factor, which is introduced to avoid size effects. The CSM defined in Eq. (1) is independent of the position, orientation, and size of the original structure. The values of $S(G)$ are between 0 (when the original structure is symmetric) and 100 when the nearest structure of $G$ symmetry reduces to a point in space. All CSM calculations were performed on the carbon skeleton of the molecules, excluding the hydrogen atoms in order to reduce numerical cost. These calculations were performed with the CSM code of Avnir et $\mathrm{al}^{8,41}$.

\section{RESULTS AND DISCUSSION}

Correlation between temperature and distortion. We start by looking at the general effect of temperature on the CSM. To this end we selected three molecules (bullvalene, barbaralane and semibullvalene, see Scheme 1) and followed their dynamics in the gas-phase at three different temperatures. Their intramolecular rearrangements along the IRC conserve a reflection symmetry (hence $S\left(C_{S}\right)=0$ by definition). However, at non-zero temperatures $S\left(C_{S}\right)$ show characteristic distributions exemplified in Fig.1 for barbaralane. We note that at the TS, barbaralane has two reflection planes, marked $\sigma_{1}$ and $\sigma_{2}$ (Fig. 2). The relevant reflection plane (labeled $\sigma_{1}$ ) also characterizes the reactant and product. 


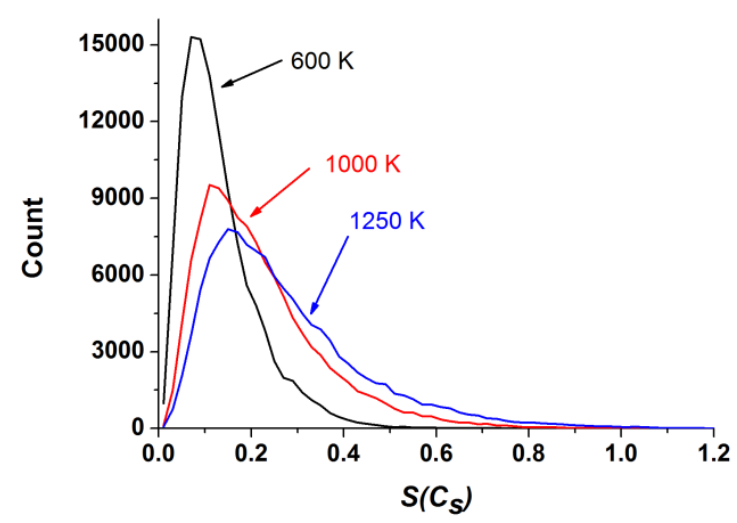

Figure 1: Symmetry conservation of barbaralane as a function of temperature. Shown are the histograms of $S\left(C_{S}\right)$ at $600 K$ (black), $1000 K$ (red) and $1250 K$ (blue). Each histogram is based on 119,948 AIMD data points with bin size of 0.02 .

The histograms in Fig. 1 are characterized by a bell shape with a long tail that leads to high standard deviation of the average values (c.a. $65 \%$ for all temperatures). Yet, both the sign test ${ }^{42}$ and the Wilcoxon matched pairs test ${ }^{43}$ show that the difference between the various distributions is statistically significant $(p=0.00)$. As opposed to the average, the median is not affected by extreme values and can therefore be used as a measure for the distortion level at each temperature. Our results show that the distortion level of barbaralane fluctuates around a small median value of 0.11 at $600 \mathrm{~K}, 0.19$ at $1000 \mathrm{~K}$ and 0.23 at $1250 K$ and increases with temperature. Similar results were obtained for bullvalene and semibullvalene. Recent results by Bredtmann and Paulus ${ }^{44}$ support these results by showing that the coupled electronic and nuclear rearrangement associated with the Cope rearrangement of semibullvalene occurs asynchronously. Furthermore, when one of the hydrogen atoms of semibullvalene is substituted by either a methyl group or an amino group, the distortion of the original semibullvalene skeleton of eight carbon atoms 
follows the same trend as semibullvalene with negligible effect on the medians. Histograms of all other systems are provided as supplementary material.

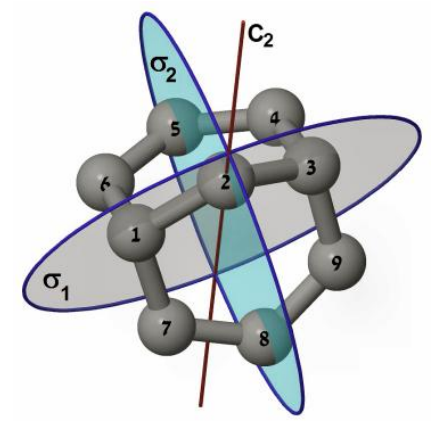

Figure 2: The TS of barbaralane. In the reaction bonds $\mathrm{C}_{6}-\mathrm{C}_{7}$ and $\mathrm{C}_{4}-\mathrm{C}_{9}$ are alternately broken and formed.

Median values for all three systems are plotted in Fig. 3. The plots clearly show a linear dependence of the distortion level on temperature. The linearity can be explained by noting that a CSM value is essentially proportional to the sum of the squares of the atomic displacements from the reference structure. Within the framework of the harmonic approximation the energy necessary for deviating from equilibrium is directly proportional to the square of this amplitude. On the other hand, this energy is proportional to the available kinetic energy, i.e., to the temperature.

Generally, the median values of $S\left(C_{S}\right)$ at each temperature are small, indicating that the corresponding mirror symmetry is reasonably conserved during the se processes, and that this level of distortion does not prevent the occurrence of the expected concerted processes, as will be shown in the next section. However, the lack of perfect $C_{s}$ symmetry implies that the concept of symmetric geometry of molecules should be used with caution. A more realistic picture is to consider such molecules as slightly chiral and even asymmetric beyond the IRC. 


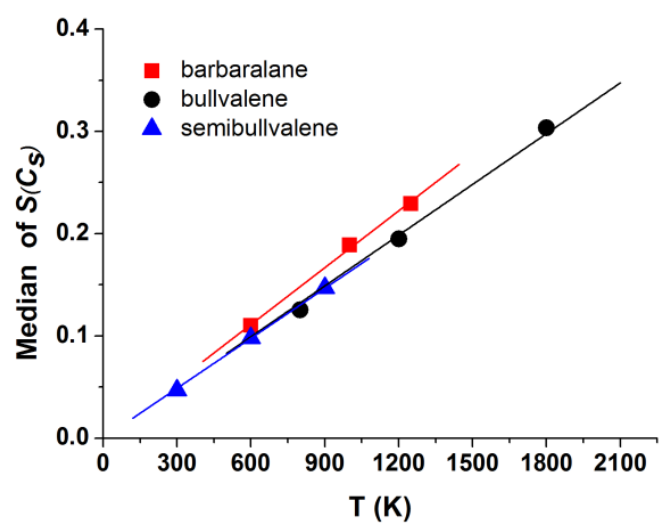

Figure 3. Distortion level (represented by the median of the $S\left(C_{s}\right)$ histogram) as a function of temperature for barbaralane (red squares), bullvalene (black circles) and semibullvalene (blue triangles). The intercept of the trend lines were set up to zero based on the IRC results. Note that the slopes are very similar because the molecules have very similar bonding arrangements.

Symmetry at elevated temperatures. Fig. 4 presents the symmetry and energy profiles of the Cope rearrangement of barbaralane along the IRC. As discussed above, $S\left(C_{S}\right)$ (with respect to $\sigma_{1}$ in Fig. 2) is zero along the IRC. On the other hand, $S\left(C_{2}\right)$ has a minimum point at the TS, and is equivalent to $S\left(C_{s}-2\right)$ (the CSM with respect to $\sigma_{2}$ in Fig. 2), throughout the whole path. AIMD results presented in Fig. 5 show that even at high temperatures excellent correlation exists between $S\left(C_{2}\right)$ and $S\left(C_{s}-2\right)$ indicating that the deviation from $C_{2}$ symmetry is equivalent to the deviation from $C_{2 v}$ symmetry, therefore $S\left(C_{2}\right)$ is sufficient to describe the deviation from the TS geometry. Furthermore, dynamical fluctuations are not random and the motion of symmetrically equivalent atoms is highly correlated. On the other hand, the evolution of $S\left(C_{s}-2\right)$ versus $S\left(C_{s}\right)$ is uncorrelated. This implies that the intramolecular transformations have a negligible effect 
on the conservation of the mirror symmetry even at high temperatures. In other words, the WH rules are obeyed to a good approximation that allows us to discriminate between TS and reactant/product geometries based on symmetry.

With this understanding in hand we can use CSMs as reaction coordinates. Note that typical reaction coordinates used for following concerted reactions (such as bond distances of the breaking and forming bonds) cannot uncover the strongly correlated motion of the symmetrically equivalent atoms as they are not collective in nature and they carry no direct information about the carbon framework. We postulate that other cage-like systems can feature symmetry conservation during high temperature motion.

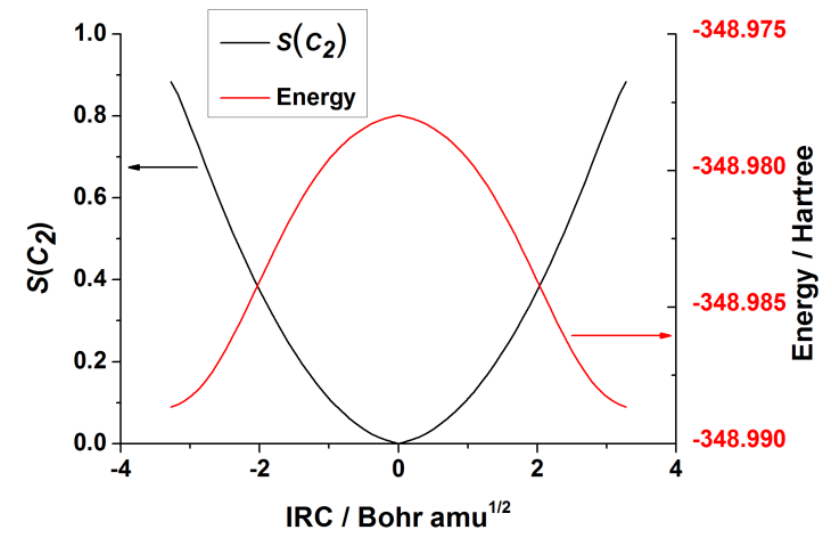

Figure 4: Symmetry and energy profiles of the Cope rearrangement of barbaralane along the IRC. Black line: $S\left(C_{2}\right)$ (left scale). Red line: Energy (right scale). 


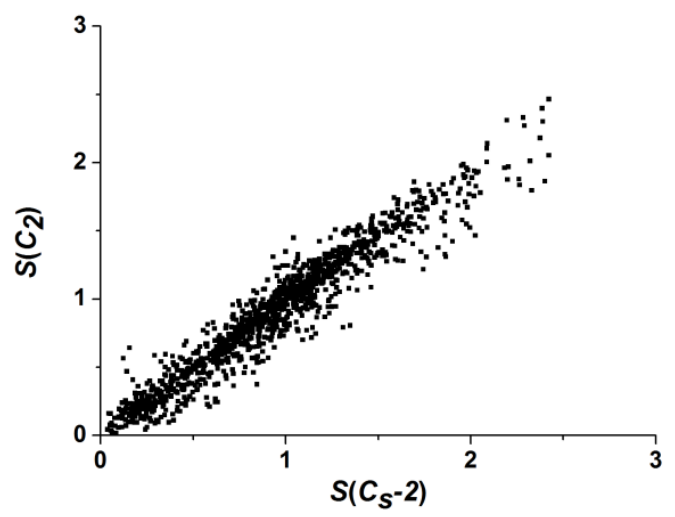

Figure 5: Correlation between $S\left(C_{2}\right)$ and $S\left(C_{s}-2\right)$ Symmetry of the Cope rearrangement of barbaralane at $1000 \mathrm{~K}$ for a time period of $6 \mathrm{ps}$.

NICS-CSM correlations for barbaralane. The WH symmetry rules ${ }^{28,45}$ and the aromaticity theory of Zimmerman ${ }^{46}$ and Dewar ${ }^{47}$ imply that the concerted rearrangement of barbaralane features an aromatic TS and the temporal aromaticity can be characterized by the NICS value. Earlier calculations ${ }^{38}$ have demonstrated that the extent of aromaticity measured by the NICS is an excellent indicator of the reaction progress for barbaralane. Fig. 6a presents the correlation between the NICS measure of aromaticity and the symmetry measure $S\left(C_{2}\right)$ along the IRC. Accordingly, the system becomes more aromatic when it approaches the TS, where the NICS value is the most negative and the CSM value is closest to zero. This correlation is not limited to the IRC and can be seen throughout the whole simulation as exemplified in Fig. $6 \mathrm{~b}$ for a time period of 6 ps taken from the $1000 K$ trajectory. Although the atomic fluctuations are large at $1000 K$, the symmetry-aromaticity correlation is remarkably retained, although with a wider NICS range. To the best of our knowledge, this is the first time a correlation between aromaticity and the degree of symmetry is demonstrated. 

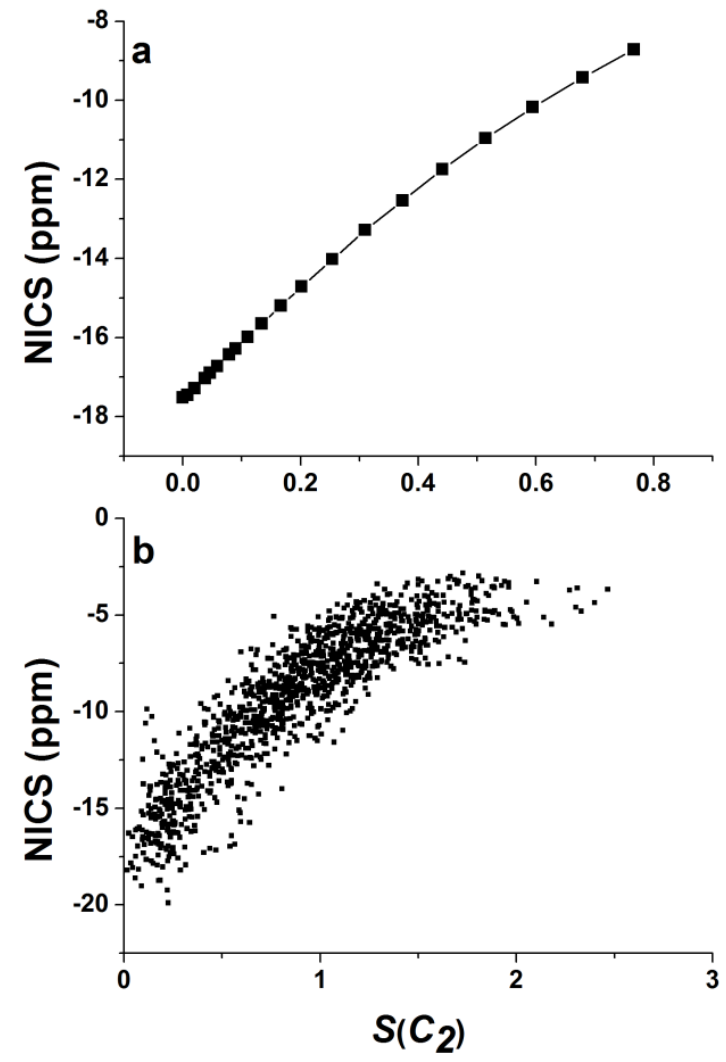

Figure 6: NICS versus CSM for barbaralane. a. Along the IRC path; b. For a time interval of $6 p s$ at $1000 \mathrm{~K}$. Data was sampled every $5 \mathrm{fs}$.

CSM as a reaction coordinate. In the following we show how the CSM can be used as a powerful reaction coordinate. As an example, we selected bullvalene. The Cope rearrangement of bullvalene is very complex: it involves $10 ! / 3=1,209,600$ different isomers that are chemically identical but differ in their connectivity ${ }^{48,49}$, implying that the sets of symmetrically equivalent atoms are different in each bullvalene configuration. The reactant and product of each rearrangement reaction belong to the $C_{3 v}$ point group and the TS belongs to the $C_{2 v}$ point group. Fig. 7 presents the structures of the reactant (A), product (B) and the TS of bullvalene along the IRC, together with their main rotation 
axes. For a given reactant geometry, each of the three C-C bonds of the cyclopropane ring are equally likely to break, leading to different TS structures. Each of these TS-s creates a different product. In Fig. 7 the bond $C_{7} C_{9}$ (structure A) was broken to form the TS and the formation of the new bond $C_{4}-C_{5}$ creates the product (structure B). Clearly, selection of a single reaction coordinate to describe this variety of configurations and reaction channels are far from obvious. Still, it is possible to distinguish between the reactant and the product by specifying the permutation that defines the $C_{3}$ rotation (i.e., the list of equivalent atoms replacing each other by the $C_{3}$ symmetry operation). The $C_{3}$ rotation axis of structure $\mathbf{A}$ in Fig. 7 goes through atom 2 permuting three triplets of atoms: $(1,4,5),(3,6,10)$ and $(7,8,9)$ while for structure $\mathbf{B}$ the axis goes through atom 8 permuting different triplets: $(2,4,5),(1,6,10)$ and $(3,7,9)$. Each such permutation can be given a serial number in order to distinguish the various geometries. Similarly, the TS is identified by its $C_{2}$ symmetry.

We followed the dynamics of the Cope rearrangement of bullvalene by calculating $S\left(C_{2}\right)$ and $S\left(C_{3}\right)$ as a function of time, without assuming any particular permutation. If at a given time, the distance of the molecular structure from $C_{2}$ symmetry is smaller than its distance from $C_{3}$ symmetry, then the system has a TS-like geometry. Otherwise, it has a reactant/product-like geometry. Reactants and products can be distinguished by the specific permutation. A successful TS crossing can be identified when two conditions are fulfilled: 1) a positive CSM difference, $\left(S\left(C_{3}\right)-S\left(C_{2}\right)>0\right)$ and 2) a change of the $C_{3}$ permutation. An unsuccessful TS visit (i.e. TS recrossing) happens when the first condition is fulfilled but the second is not. Fig. 8 presents the CSM difference $S\left(C_{3}\right)$ $S\left(C_{2}\right)$ as a function of time for the first $40 \mathrm{ps}$ of the simulation at $800 \mathrm{~K}$. Only positive 
values of the CSMs difference are shown i.e., the plot indicates situations where the thermal fluctuations bring the molecule close to a TS crossing. The blue line (right scale) marks the stages of the reactions: $\mathbf{1}$ and $\mathbf{2}$ are configurationally different bullvalene states whereas $\mathbf{3}$ is a TS-crossing (permutation change) event. In contrast, the black peaks indicate unsuccessful TS recrossing events. See supplementary material for the results at $1200 \mathrm{~K}$ and $1800 \mathrm{~K}$.

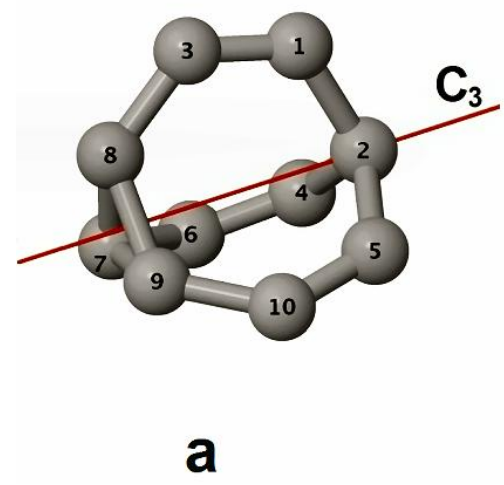

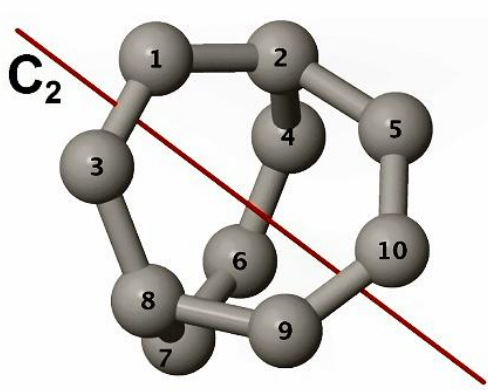

b

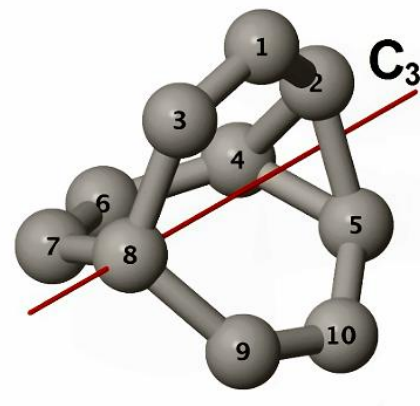

C

Figure 7: The Cope rearrangement of bullvalene. a. and c. reactant and product geometries with $C_{3}$ rotation axis; b. TS geometry with $C_{2}$ rotation axis.

As is evident from Fig. 8, the frequency of TS recrossing is significantly higher than that of the successful reactions. This demonstrates that the rearrangement reaction is accompanied by a significant number of unsuccessful TS visits. Putting in numbers, there were 6 successful TS crossing events and 252 TS recrossing events at $800 \mathrm{~K}$ over a time period of $100 \mathrm{ps}$. In other words once a TS geometry is reached, the probability that it will lead to product geometry is only $2.3 \%$. Naturally, the overall number of reactions increases with temperature. There were 31 successful TS crossing for 100 ps simulation time at $1200 K$ and 106 for $80 \mathrm{ps}$ at $1800 K$ (see supplementary material). The probability for TS geometry to form a product was $11.3 \%$ and $11.6 \%$ respectively. Longer simulation time is needed for a more accurate statistical analysis from which the 
kinetics parameters can be estimated ${ }^{38}$. The above results imply though that at room temperature the probability for a rearrangement reaction is significantly lower. The power of this methodology is in its ability to grasp the important processes from an enormous amount of structures and provide a clear and visual way to display them in one single plot.

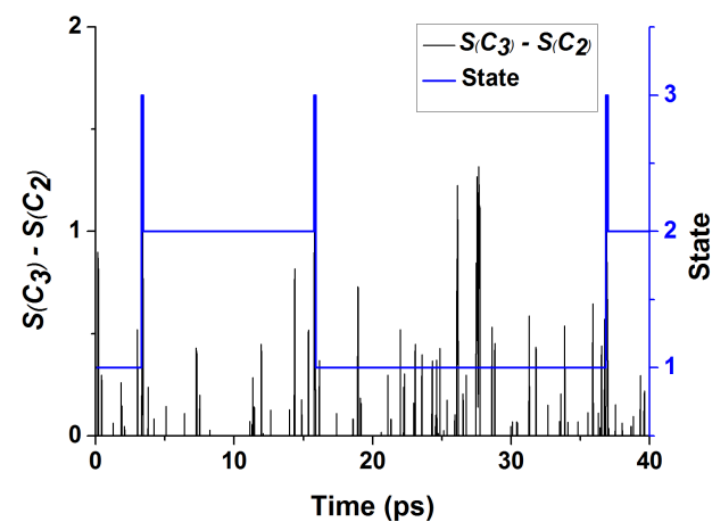

Figure 8: The CSM difference $\left(S\left(C_{3}\right)-S\left(C_{2}\right)\right)$ (black line, left scale) and the state index (blue line, right scale) for bullvalene as a function of time at $800 \mathrm{~K}$. The first $40 \mathrm{ps}$ of the simulation are shown.

CSM distribution and the substitution effect. For a conserved symmetry operation, the shape of the CSM distribution, shown in Fig. 1, features one peak and a long tail. For a non-conserved symmetry operation (i.e., symmetry operation belonging to the TS but not to the reactant/product) the shape of the CSM distribution has two peaks and a long tail. The first peak describes the probability to find the system in a TS-like geometry, while the second, with a larger CSM value, represents the probability to find the system in a reactant/product-like geometry. As an example, Fig. 9 presents the $S\left(C_{2}\right)$ distribution of semibullvalene at $300 \mathrm{~K}$. The black line represents the $S\left(C_{2}\right)$ distribution with one peak 
at 0.045 and the other at 0.86 . The red line with a scale on the right is the cumulative probability of $S\left(C_{2}\right)$. Generally, the system has a TS-like geometry when $S\left(C_{2}\right) \leq 0.285$ which is the CSM value at the minimum point separating the two peaks of the distribution curve. The cumulative probability at this point is $23.1 \%$. In other words, out of $48 \mathrm{ps}$ (total simulation time), the system had a TS-like geometry for about $11.1 \mathrm{ps}$.

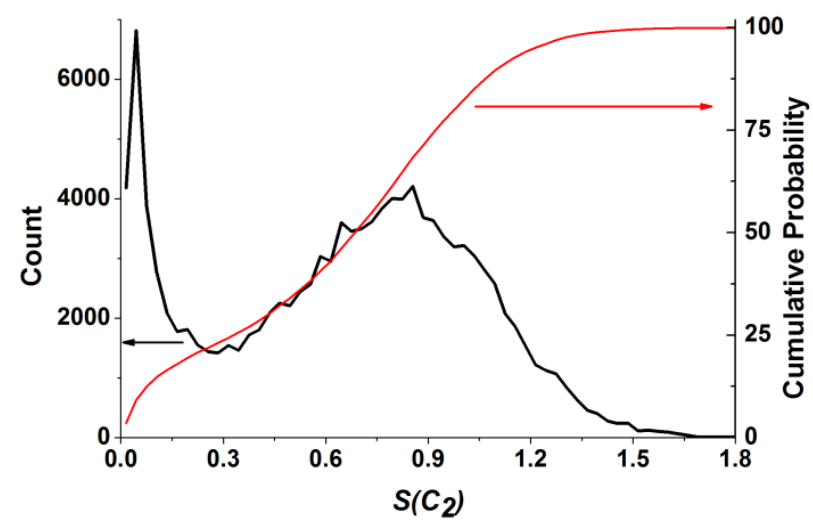

Figure 9: $S\left(C_{2}\right)$ distribution (black line, left scale) and the corresponding cumulative probability (red line, right scale) for semibullvalene at $300 \mathrm{~K}$. Based on 120,000 data points sampling $48 \mathrm{ps}$ with a bin size of 0.03 .

The CSM is a normalized function therefore it can be used to compare different systems. By comparing the shapes of CSM distributions we gain new insight into the relative reactivity of the studied reactions. Both temperature and substitution can yield a difference in the CSM distributions' shape, and we will discuss both of these effects. Let us examine first the temperature effect on reactivity. Fig. 10 presents $S\left(C_{2}\right)$ distribution for semibullvalene at three temperatures: $300 K, 600 K$ and $900 K$. Increasing the temperature results in larger atomic fluctuations and larger distortions. On the other hand, at higher temperatures the population of the TS is higher and since the TS is more 
symmetric than the reactant or product, we expect the distortion level to decrease. The interplay of these two effects determines the distribution of $S\left(C_{2}\right)$. Both peaks become wider as the temperature increases but their relative weights also change. The evolution of each curve with temperature shows an overall increase of the time the system stays in a TS-like geometry. We define the border line between the TS-like and reactant/productlike geometries at the minimum after the first peak. The position of this line and the cumulative probabilities are $(0.285,23.1 \%)$ at $300 K,(0.465,43.9 \%)$ at $600 K$ and $(0.735$, $44.2 \%)$ at $900 \mathrm{~K}$. These numbers can be interpreted respectively as the maximum level of distortion of the TS at each temperature, and the total percentage of molecules that can be found at this (or lower) level of distortion.

The effect of temperature on the reactivity of 3-aminosemibullvalene is similar, although less profound. Here $S\left(C_{2}\right)$ was calculated for the carbon skeleton of the molecule. The shape of the $S\left(C_{2}\right)$ distributions shown in Fig. 11a clearly indicates that the system is much more reactive than semibullvalene since the height of the first peak is significantly larger while the second peak is much shallower, regardless of temperature. At the minimum point of each curve the CSM value and the cumulative probability to find the system with a TS-like geometry are $(0.255,52.3 \%)$ at $300 K$ and $(0.375,57.1 \%)$ at $600 \mathrm{~K}$. At $900 \mathrm{~K}$ the curve is rather monotonic although a very shallow minimum point can be identified at $(0.525,66.0 \%)$. 


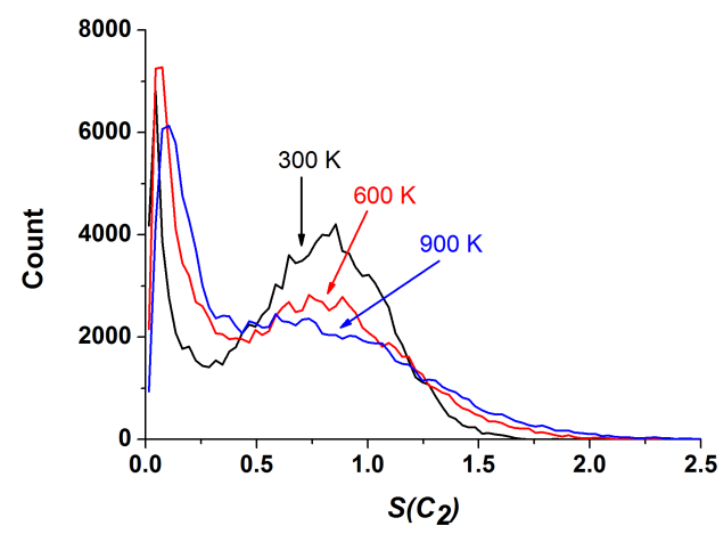

Figure 10: $S\left(C_{2}\right)$ distribution for semibullvalene at $300 K$ (black), $600 K$ (red) and 900 $K$ (blue). Each curve is based on 120,000 data points sampling 48 ps with a bin size of 0.03 .

At this point two remarks have to be made: First, as opposed to semibullvalene, the reactant and product of 3-aminosemibullvalene are different but the present CSM analysis does not distinguish between them. Indeed, the relative position of the amino substituent with respect to the breaking $\mathrm{C}-\mathrm{C}$ bond defines the reactant and product. However, the amino group (and similarly the methyl ligand) is not included into the analysis in order to maintain the $\mathrm{C}_{2}$ symmetry of the TS in the cope-reactions. The second, more important remark is that the shape of the distribution of $S\left(C_{2}\right)$ is very similar to the distribution obtained for a conserved symmetry operation (like the $S\left(C_{s}\right)$ distribution for barbaralane in Fig. 1). This implies that at high temperatures the system is fluctuating around the TS with occasional reactant/product visits. This result is in accordance with the prediction of Zhang et al. that upon suitable substitution the TS geometry of semibullvalene may become frozen $^{50}$, suggesting the TS could be homoaromatic ${ }^{51,52}$. The substitution effect is further strengthened by considering 2,6- 
diazasemibullvalene for which the structure with perfect $C_{2}$ symmetry on the ground state is a delocalized homoaromatic intermediate with an energy lower by only $0.15 \mathrm{kcal} / \mathrm{mol}$ from two slightly distorted TS-s $\left(S\left(C_{2}\right)=0.0683\right)$. Consequently, the $S\left(C_{2}\right)$ distribution has only one peak and $C_{2}$ symmetry is approximately conserved even at $300 \mathrm{~K}$ (Fig. 11b).
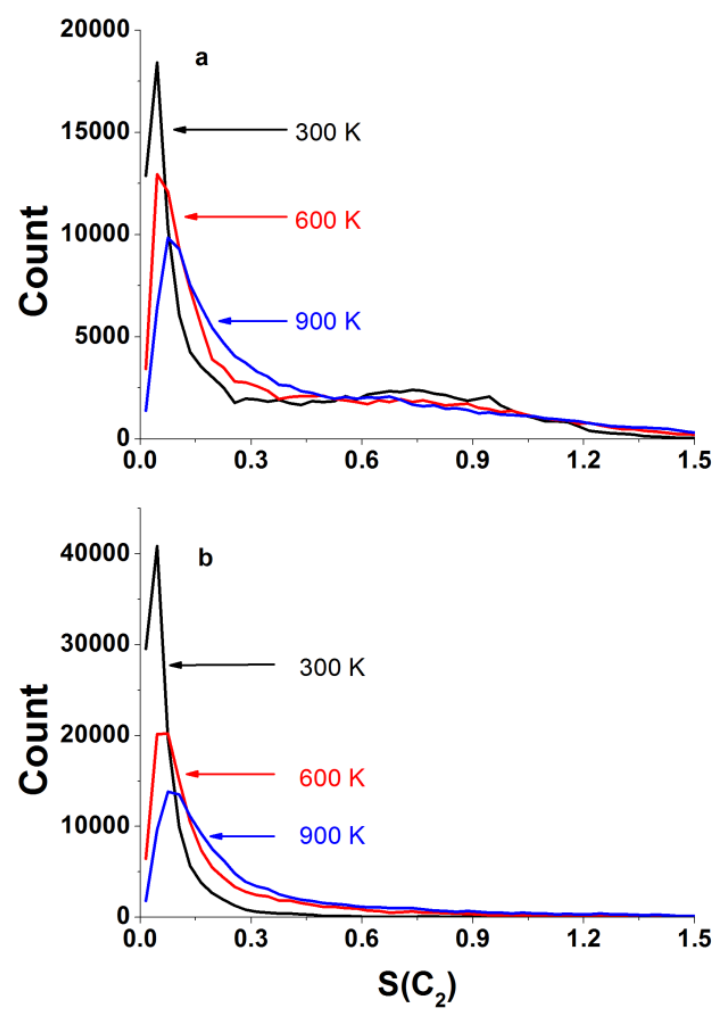

Figure 11: $S\left(C_{2}\right)$ distribution for a) 3-aminosemibullvalene and b) 2,6diazasemibullvalene at $300 \mathrm{~K}$ (black), $600 \mathrm{~K}$ (red) and $900 \mathrm{~K}$ (blue). Each curve is based on 120,000 data points sampling 48 ps with a bin size of 0.03 .

The overall effect of both substitution and temperature can be seen in Fig. 12 that presents the median of $S\left(C_{2}\right)$ versus temperature for all systems. Let us first consider the temperature effect. Generally we expect the reactivity to increase with temperature, i.e., 
that the population of higher energy states will increase with temperature. For semibullvalene and 3-methylsemibullvalene, increased accessibility of the TS geometry at high temperature is more significant than the distortions caused by thermal fluctuations and the overall effect is a decrease of the median of $S\left(C_{2}\right)$ with temperature. For 3aminosemibullvalene and 2,6-diazasemibullvalene where the TS structures are more accessible, thermal fluctuations are the dominate factor leading to increased distortion at higher temperatures. As for the substitution effect, at $300 \mathrm{~K}$ the distortion difference between 3-methylsemibullvalene and semibullvalene is small, while the amino and the diaza derivatives are much more symmetric. However, as the temperature increases the difference between the systems is significantly reduced. Based on the trends in Fig. 12 we conclude that at high temperatures the nature of the substituent plays a secondary role, compared with the temperature itself, as far as the overall symmetry is concerned.

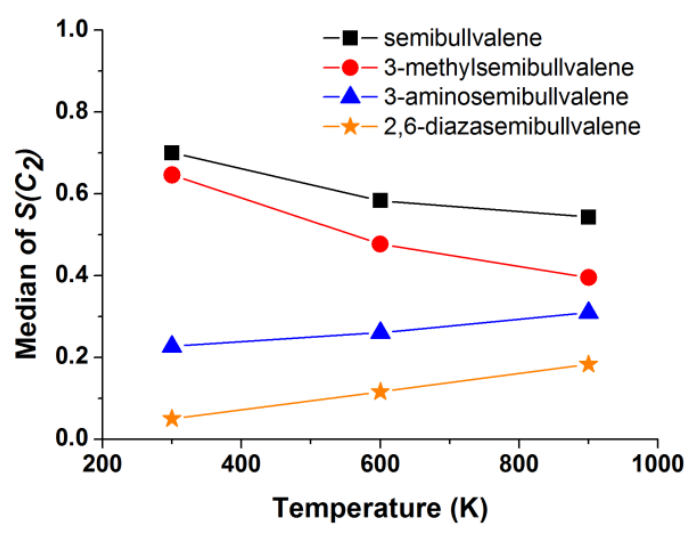

Figure 12: Median of $S\left(C_{2}\right)$ versus temperature for a) semibullvalene (black squares); b) 3-methylsemibullvalene (red circles); 3-aminosemibullvalene (blue triangles) and d) 2,6diazasemibullvalene (orange stars). Each point is based on 120,000 data points sampling $48 p s$ of simulation. 


\section{CONCLUSIONS}

In the present study we proposed a simple and powerful idea, namely the use of continuous symmetry measures as reaction coordinates and showed how it can be efficiently employed to analyze reaction mechanisms and monitor the progress of concerted transformations at elevated temperatures. In particular, applying the CSM variable as a single collective variable we demonstrated that its variation with temperature is linear and its distribution can reveal hidden properties of the finitetemperature behavior of fluxional molecules. By following the statistical behavior of nonconserved symmetry operations, we showed that polarity induced by the substituent tends to stabilize the TS geometry of semibullvalene derivatives, where 2,6diazasemibullvalene experiences the largest effect due to a homoaromatic intermediate. Other diaza-derivatives of semibullvalene, suggested by Zhang et $\mathrm{al}^{50}$, may experience a more profound effect. On the other hand, thermal fluctuations lead to distortion of the geometry, and the mechanism is a gentle interplay between these two factors. A question may thus be asked - can a system be designed such that the median will be independent of temperature? We leave this question for a future work.

\section{ACKNOWLEDGEMENTS}

Supported by The Open University of Israel's Research Fund, grants no. 101368 and 101594 and by the OTKA grant K 101115. We thank Prof. David Avnir (The Hebrew University of Jerusalem, Israel) for the CSM codes and Sagiv Barhoom and Limor Radozkowicz (The Open University) for their help in programming. 


\section{SUPPORTING INOFRMATION}

Plots of the $S(C s)$ distributions for bullvalene and semibullvalene as a function of temperature, CSM analysis of bullvalene at $1200 \mathrm{~K}$ and $1800 \mathrm{~K}$ and Cartesian coordinates and electronic energies for the reactants, products and TS-s of all compounds in this study, optimized at the B3LYP/6-311+G* level. This material is available free of charge via the Internet at http://pubs.acs.org.

\section{REFERENCES}

(1) Fukui, K. J. Phys. Chem. 1970, 74, 4161.

(2) Fukui, K. Acc. Chem. Res. 1981, 14, 363.

(3) Sun, L. P.; Song, K. Y.; Hase, W. L. Science 2002, 296, 875.

(4) Ammal, S. C.; Yamataka, H.; Aida, M.; Dupuis, M. Science 2003, 299, 1555.

(5) Sprik, M. Faraday Discuss. 1998, 110, 437.

(6) Branduardi, D.; Gervasio, F. L.; Parrinello, M. J. Chem. Phys. 2007, 126, 054103.

(7) Laio, A.; Gervasio, F. L. Rep. Prog. Phys. 2008, 71, 126601.

(8) Zabrodsky, H.; Peleg, S.; Avnir, D. J. Am. Chem. Soc. 1992, 114, 7843.

(9) Tuvi-Arad, I.; Avnir, D. J. Math. Chem. 2010, 47, 1274.

(10) Pinsky, M.; Dryzun, C.; Casanova, D.; Alemany, P.; Avnir, D. J. Comput. Chem. 2008, 29, 2712.

(11) Zabrodsky, H.; Avnir, D. J. Am. Chem. Soc. 1995, 117, 462.

(12) Dryzun, C.; Avnir, D. Chemphyschem 2011, 12, 197.

(13) Zabrodsky, H.; Peleg, S.; Avnir, D. J. Am. Chem. Soc. 1993, 115, 8278.

(14) Zabrodsky, H.; Peleg, S.; Avnir, D. J. Am. Chem. Soc. 1993, 115, 11656.

(15) Alvarez, S.; Alemany, P.; Casanova, D.; Cirera, J.; Llunell, M.; Avnir, D. Coord. Chem. Rev. 2005, 249, 1693.

(16) Yogev-Einot, D.; Avnir, D. Tetrahedron-Asymmetr 2006, 17, 2723.

(17) Keinan, S.; Avnir, D. J. Am. Chem. Soc. 2000, 122, 4378.

(18) Alvarez, S. J. Am. Chem. Soc. 2003, 125, 6795.

(19) Dryzun, C.; Mastai, Y.; Shvalb, A.; Avnir, D. J. Mater. Chem. 2009, 19, 2062.

(20) Casanova, D.; Alemany, P. PCCP 2010, 12, 15523.

(21) Kanis, D. R.; Wong, J. S.; Marks, T. J.; Ratner, M. A.; Zabrodsky, H.; Keinan, S.; Avnir, D. J. Phys. Chem. 1995, 99, 11061.

(22) Sheka, E. F.; Razbirin, B. S.; Nelson, D. K. J. Phys. Chem. A 2011, 115, 3480.

(23) Simons, R. S.; Galat, K. J.; Bradshaw, J. D.; Youngs, W. J.; Tessier, C. A.; Aullon, G.; Alvarez, S. J. Organomet. Chem. 2001, 628, 241.

(24) Tuvi-Arad, I.; Avnir, D. J. Org. Chem. 2011, 76, 4973.

(25) Tuvi-Arad, I.; Avnir, D. Chem. Eur. J. 2012, 18, 10014. 
(26) Graulich, N. Wiley Interdiscip. Rev.-Comput. Mol. Sci. 2011, 1, 172.

(27) Marx, D.; Hutter, J. Ab Initio Molecular Dynamics, Basic Theory and Advanced Methods; Cambridge University Press: United Kingdom, 2009.

(28) Woodward, R. B.; Hoffmann, R. Angew. Chem. Int. Ed. 1969, 8, 781.

(29) Woodward, R. B.; Hoffmann, R. J. Am. Chem. Soc. 1965, 87, 2511.

(30) CP2K Open Source Molecular Dynamics Software; http://www.cp2k.org/.

(31) Becke, A. D. J. Chem. Phys. 1993, 98, 5648.

(32) Lee, C. T.; Yang, W. T.; Parr, R. G. Phys. Rev. B 1988, 37, 785.

(33) Goedecker, S.; Teter, M.; Hutter, J. Phys. Rev. B 1996, 54, 1703.

(34) Martyna, G. J.; Klein, M. L.; Tuckerman, M. J. Chem. Phys. 1992, 97, 2635.

(35) Frisch, M. J.; Trucks, G. W.; Schlegel, H. B.; Scuseria, G. E.; Robb, M. A.; Cheeseman, J. R.; Scalmani, G.; Barone, V.; Mennucci, B.; Petersson, G. A.; Nakatsuji, H.; Caricato, M.; Li, X.; Hratchian, H. P.; Izmaylov, A. F.; Bloino, J.; Zheng, G.; Sonnenberg, J. L.; Hada, M.; Ehara, M.; Toyota, K.; Fukuda, R.; Hasegawa, J.; Ishida, M.; Nakajima, T.; Honda, Y.; Kitao, O.; Nakai, H.; Vreven, T.; Montgomery, J., J. A. ; Peralta, J. E.; Ogliaro, F.; Bearpark, M.; Heyd, J. J.; Brothers, E.; Kudin, K. N.; Staroverov, V. N.; Kobayashi, R.; Normand, J.; Raghavachari, K.; Rendell, A.; Burant, J. C.; Iyengar, S. S.; Tomasi, J.; Cossi, M.; Rega, N.; Millam, N. J.; Klene, M.; Knox, J. E.; Cross, J. B.; Bakken, V.; Adamo, C.; Jaramillo, J.; Gomperts, R.; Stratmann, R. E.; Yazyev, O.; Austin, A. J.; Cammi, R.; Pomelli, C.; Ochterski, J. W.; Martin, R. L.; Morokuma, K.; Zakrzewski, V. G.; Voth, G. A.; Salvador, P.; Dannenberg, J. J.; Dapprich, S.; Daniels, A. D.; Farkas, Ö.; Foresman, J. B.; Ortiz, J. V.; Cioslowski, J.; Fox, D. J.; Gaussian, Inc. : Wallingford CT, 2009.

(36) Chen, Z. F.; Wannere, C. S.; Corminboeuf, C.; Puchta, R.; Schleyer, P. V. Chem. Rev. 2005, 105, 3842.

(37) Schleyer, P. V.; Maerker, C.; Dransfeld, A.; Jiao, H. J.; Hommes, N. J. Am. Chem. Soc. 1996, 118, 6317.

(38) Rozgonyi, T.; Bartok-Partay, A.; Stirling, A. J. Phys. Chem. A 2010, 114, 1207.

(39) Vosko, S. H.; Wilk, L.; Nusair, M. Can. J. Phys. 1980, 58, 1200.

(40) Stephens, P. J.; Devlin, F. J.; Chabalowski, C. F.; Frisch, M. J. J. Phys. Chem. 1994, 98, 11623.

(41) Pinsky, M.; Casanova, D.; Alemany, P.; Alvarez, S.; Avnir, D.; Dryzun, C.; Kizner, Z.; Sterkin, A. J. Comput. Chem. 2008, 29, 190.

(42) Electronic Statistics Textbook; http://www.statsoft.com/textbook/: Tulsa, OK: StatSoft, 2012.

(43) Wilcoxon, F. Biometrics Bulletin 1945, 1, 80.

(44) Bredtmann, T.; Paulus, B. Journal of Chemical Theory and Computation 2013, 9, 3026.

(45) Day, A. C. J. Am. Chem. Soc. 1975, 97, 2431.

(46) Zimmerman, H. E. Acc. Chem. Res. 1971, 4, 272.

(47) Dewar, M. J. S. Angewandte Chemie International Edition in English 1971, 10,

761.

(48) Zivkovic, T. P. Croat. Chem. Acta 1996, 69, 215.

(49) Ault, A. J. Chem. Educ. 2001, 78, 924.

(50) Zhang, S.; Wei, J.; Zhan, M.; Luo, Q.; Wang, C.; Zhang, W.-X.; Xi, Z. J. Am. Chem. Soc. 2012, 134, 11964. 
(51) Allan, C. S. M.; Rzepa, H. S. J. Org. Chem. 2008, 73, 6615.

(52) Griffiths, P. R.; Pivonka, D. E.; Williams, R. V. Chemistry-a European Journal 2011, 17, 9193.

\section{TOC GRAPHICS}

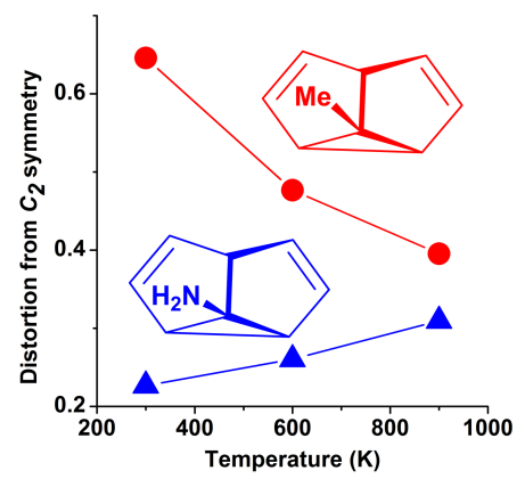




\title{
Supplementary Material
}

\section{Effect of temperature and substitution on Cope rearrangement - A symmetry perspective}

\author{
Inbal Tuvi-Arad ${ }^{\mathrm{a} *}$, Tamás Rozgonyi ${ }^{\mathrm{b}}$ and András Stirling ${ }^{\mathrm{c}}$
}

${ }^{a}$ Department of Natural Sciences, The Open University of Israel, 1 University Rd., Raanana 43107, Israel, inbaltu@openu.ac.il

${ }^{\mathrm{b}}$ Institute of Materials and Environmental Chemistry, Research Center for Natural Sciences of the HAS, Pusztaszeri ut 59-67, Budapest 1025, Hungary

${ }^{\mathrm{c}}$ Institute of Organic Chemistry, Research Center for Natural Sciences of the HAS, Pusztaszeri ut 59-67, Budapest 1025, Hungary, stirling.andras@ttk.mta.hu

\section{Supplementary Material}

Symmetry conservation of bullvalene and semibullvalene as a function of 1 temperature

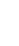

CSM analysis of bullvalene at $1200 \mathrm{~K}$ and $1800 \mathrm{~K}$

Cartesian coordinates and electronic energies

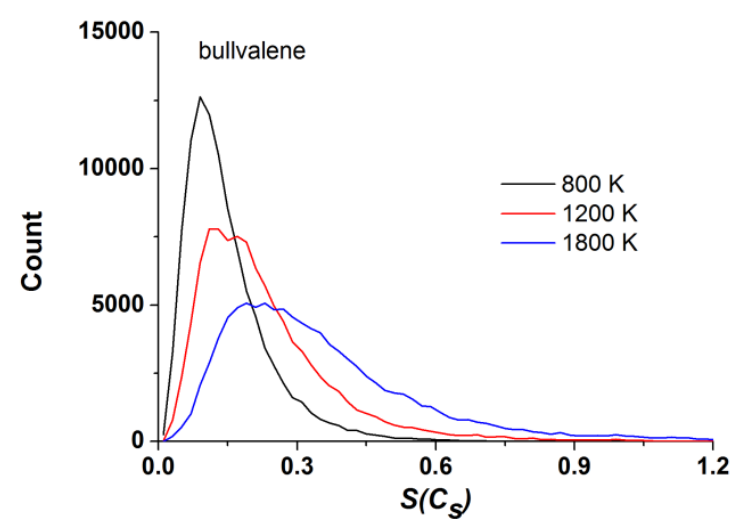

Fig. 1: Symmetry conservation of bullvalene as a function of temperature. Shown are the histograms of $S\left(C_{s}\right)$ at $800 K$ (black), $1200 K$ (red) and $1800 K$ (blue). Each histogram is based on 100,000 data points with bin size of 0.02 . 


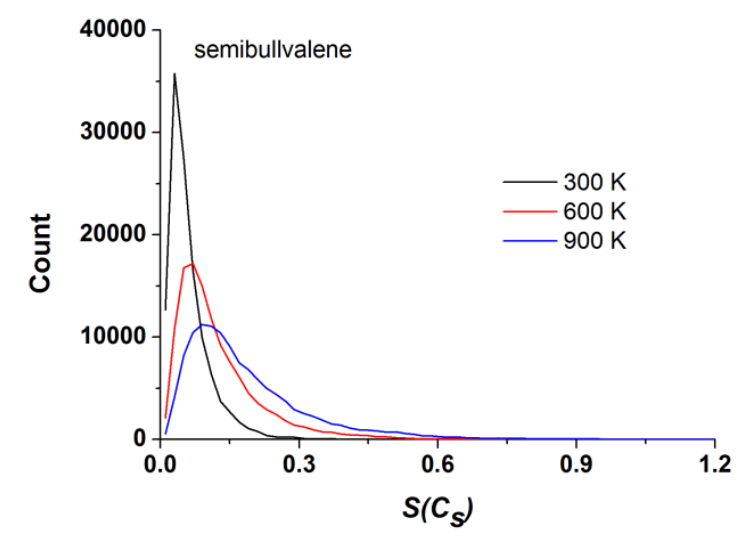

Fig. 2: Symmetry conservation of semibullvalene as a function of temperature. Shown are the histograms of $S\left(C_{s}\right)$ at $300 K$ (black), $600 K$ (red) and $900 K$ (blue). Each histogram is based on 120,000 data points with bin size of 0.02 .

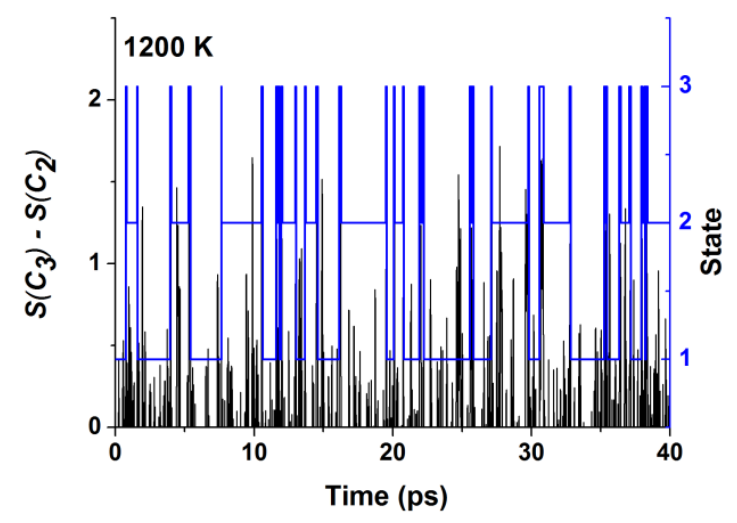

Fig. 3. The CSM difference $S\left(C_{3}\right)-S\left(C_{2}\right)$ (black line, left scale) and the state index (blue line, right scale) for bullvalene as a function of time at $1200 \mathrm{~K}$.

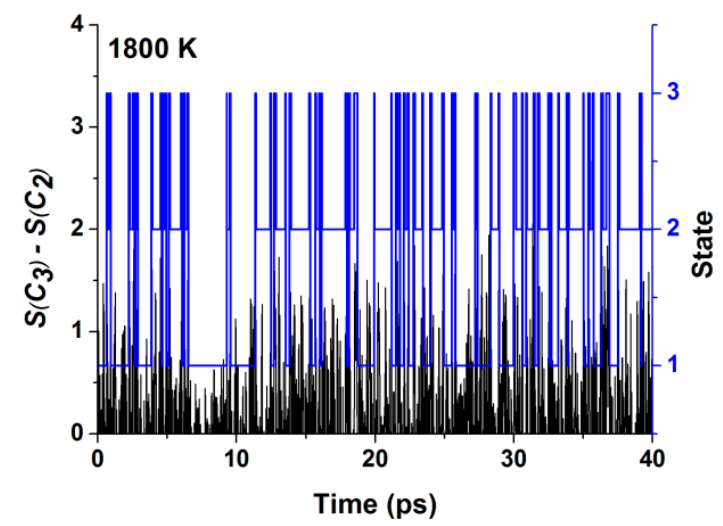

Fig. 4. The CSM difference $S\left(C_{3}\right)-S\left(C_{2}\right)$ (black line, left scale) and the state index (blue line, right scale) for bullvalene as a function of time at $1800 \mathrm{~K}$. 


\section{Cartesian Coordiantes and Electronic Energies of Barbaralane and Bullvalene}

\begin{tabular}{lrrr}
\multicolumn{3}{c}{ Barbaralane - reactant } & \multicolumn{3}{c}{ Energy $\left(\mathrm{B} 3 \mathrm{LYP} / 6-311+\mathrm{G}^{*}\right):-348.988731$ Hartree } \\
$\mathrm{C}$ & 1.23489 & -0.79861 & 0.00000 \\
$\mathrm{C}$ & 1.43182 & 0.70114 & 0.00000 \\
$\mathrm{C}$ & 0.05152 & 1.40780 & 0.00000 \\
$\mathrm{C}$ & -0.75453 & 0.95978 & 1.20327 \\
$\mathrm{C}$ & -0.75453 & -0.33992 & 1.53919 \\
$\mathrm{C}$ & 0.05997 & -1.31097 & 0.79460 \\
$\mathrm{C}$ & 0.05997 & -1.31097 & -0.79460 \\
$\mathrm{C}$ & -0.75453 & -0.33992 & -1.53919 \\
$\mathrm{C}$ & -0.75453 & 0.95978 & -1.20327 \\
$\mathrm{H}$ & 1.99963 & 1.00866 & -0.88473 \\
$\mathrm{H}$ & 0.18588 & 2.49211 & 0.00000 \\
$\mathrm{H}$ & -1.38282 & 1.67726 & 1.72270 \\
$\mathrm{H}$ & -1.38282 & 1.67726 & -1.72270 \\
$\mathrm{H}$ & -1.38195 & -0.70766 & 2.34645 \\
$\mathrm{H}$ & -1.38195 & -0.70766 & -2.34645 \\
$\mathrm{H}$ & 0.14563 & -2.30414 & -1.22191 \\
$\mathrm{H}$ & 0.14563 & -2.30414 & 1.22191 \\
$\mathrm{H}$ & 2.13300 & -1.40912 & 0.00000 \\
$\mathrm{H}$ & 1.99963 & 1.00866 & 0.88473
\end{tabular}

Barbaralane - product Energy (B3LYP/6-311+G*): -348.988749 Hartree

$\begin{array}{lrrr}\mathrm{C} & 1.33273 & -0.00000 & 0.45545 \\ \mathrm{C} & 0.25849 & -0.00001 & 1.57335 \\ \mathrm{C} & -1.12067 & -0.00000 & 0.95229 \\ \mathrm{C} & -1.27245 & -0.79454 & -0.32080 \\ \mathrm{C} & -0.10780 & -1.53937 & -0.82074 \\ \mathrm{C} & 1.13650 & -1.20344 & -0.44573 \\ \mathrm{C} & 1.13650 & 1.20343 & -0.44572 \\ \mathrm{C} & -0.10780 & 1.53937 & -0.82073 \\ \mathrm{C} & -1.27245 & 0.79455 & -0.32079 \\ \mathrm{H} & 0.38912 & 0.88480 & 2.20554 \\ \mathrm{H} & -1.96453 & -0.00001 & 1.63581 \\ \mathrm{H} & -2.24810 & -1.22198 & -0.52495 \\ \mathrm{H} & -2.24811 & 1.22199 & -0.52495 \\ \mathrm{H} & -0.27893 & -2.34712 & -1.52695\end{array}$




$\begin{array}{rrrr}\mathrm{H} & -0.27893 & 2.34715 & -1.52695 \\ \mathrm{H} & 2.00493 & 1.72303 & -0.83962 \\ \mathrm{H} & 2.00491 & -1.72302 & -0.83962 \\ \mathrm{H} & 2.33227 & -0.00001 & 0.89679 \\ \mathrm{H} & 0.38912 & -0.88482 & 2.20553\end{array}$

\begin{tabular}{lccc}
\multicolumn{2}{c}{ Barbaralane - TS } & \multicolumn{2}{c}{ Energy $\left(\mathrm{B} 3 \mathrm{LYP} / 6-311+\mathrm{G}^{*}\right):-348.977961$ Hartree } \\
$\mathrm{C}$ & 1.11125 & -0.90420 & 0.00000 \\
$\mathrm{C}$ & 1.48548 & 0.57927 & 0.00000 \\
$\mathrm{C}$ & 0.20633 & 1.41768 & 0.00000 \\
$\mathrm{C}$ & -0.77681 & 0.99739 & 1.04794 \\
$\mathrm{C}$ & -0.77681 & -0.30304 & 1.53842 \\
$\mathrm{C}$ & 0.10476 & -1.25920 & 1.05016 \\
$\mathrm{C}$ & 0.10476 & -1.25920 & -1.05016 \\
$\mathrm{C}$ & -0.77681 & -0.30304 & -1.53842 \\
$\mathrm{C}$ & -0.77681 & 0.99739 & -1.04794 \\
$\mathrm{H}$ & 2.08519 & 0.81303 & -0.88504 \\
$\mathrm{H}$ & 0.41007 & 2.48955 & 0.00000 \\
$\mathrm{H}$ & -1.50803 & 1.71907 & 1.39382 \\
$\mathrm{H}$ & -1.50803 & 1.71907 & -1.39382 \\
$\mathrm{H}$ & -1.54712 & -0.60328 & 2.24291 \\
$\mathrm{H}$ & -1.54712 & -0.60328 & -2.24291 \\
$\mathrm{H}$ & 0.05553 & -2.28508 & -1.39716 \\
$\mathrm{H}$ & 0.05553 & -2.28508 & 1.39716 \\
$\mathrm{H}$ & 1.98684 & -1.55521 & 0.00000 \\
$\mathrm{H}$ & 2.08519 & 0.81303 & 0.88504
\end{tabular}

\begin{tabular}{lcccc}
\multicolumn{4}{c}{ Bullvalene - reactant } & \multicolumn{3}{c}{ Energy $\left(\mathrm{B} 3 \mathrm{LYP} / 6-311+\mathrm{G}^{*}\right):$} & -387.071741 Hartree \\
$\mathrm{C}$ & -1.07683 & 1.44415 & -0.00001 & \\
$\mathrm{C}$ & -1.55105 & 0.00071 & -0.00000 & \\
$\mathrm{C}$ & 0.21382 & 1.80269 & -0.00001 & \\
$\mathrm{C}$ & -1.07707 & -0.72179 & 1.25019 & \\
$\mathrm{C}$ & -1.07707 & -0.72180 & -1.25019 & \\
$\mathrm{C}$ & 0.21363 & -0.90189 & 1.56023 & \\
$\mathrm{C}$ & 1.36877 & -0.44340 & 0.76833 & \\
$\mathrm{C}$ & 1.36868 & 0.88742 & -0.00000 & \\
$\mathrm{C}$ & 1.36877 & -0.44341 & -0.76833 &
\end{tabular}




$\begin{array}{cccc}\mathrm{C} & 0.21363 & -0.90190 & -1.56023 \\ \mathrm{H} & -1.83726 & 2.22056 & -0.00001 \\ \mathrm{H} & -2.64291 & 0.00085 & -0.00000 \\ \mathrm{H} & 0.45698 & 2.86275 & -0.00001 \\ \mathrm{H} & -1.83770 & -1.11118 & 1.92170 \\ \mathrm{H} & -1.83769 & -1.11119 & -1.92169 \\ \mathrm{H} & 0.45652 & -1.43339 & 2.47749 \\ \mathrm{H} & 2.33124 & -0.69327 & 1.20157 \\ \mathrm{H} & 2.33138 & 1.38703 & -0.00000 \\ \mathrm{H} & 2.33124 & -0.69327 & -1.20156 \\ \mathrm{H} & 0.45652 & -1.43341 & -2.47748\end{array}$

Bullvalene - product Energy (B3LYP/6-311+G*): -387.071741 Hartree

$\begin{array}{lrrr}\mathrm{C} & -0.21382 & 1.80269 & -0.00001 \\ \mathrm{C} & -1.36868 & 0.88742 & -0.00000 \\ \mathrm{C} & 1.07683 & 1.44415 & -0.00001 \\ \mathrm{C} & -1.36877 & -0.44340 & 0.76833 \\ \mathrm{C} & -1.36877 & -0.44341 & -0.76833 \\ \mathrm{C} & -0.21363 & -0.90190 & 1.56023 \\ \mathrm{C} & 1.07707 & -0.72179 & 1.25019 \\ \mathrm{C} & 1.55105 & 0.00071 & -0.00000 \\ \mathrm{C} & 1.07707 & -0.72180 & -1.25019 \\ \mathrm{C} & -0.21363 & -0.90190 & -1.56023 \\ \mathrm{H} & -0.45698 & 2.86275 & -0.00001 \\ \mathrm{H} & -2.33138 & 1.38703 & -0.00000 \\ \mathrm{H} & 1.83726 & 2.22056 & -0.00001 \\ \mathrm{H} & -2.33124 & -0.69327 & 1.20157 \\ \mathrm{H} & -2.33124 & -0.69327 & -1.20156 \\ \mathrm{H} & -0.45652 & -1.43339 & 2.47749 \\ \mathrm{H} & 1.83770 & -1.11118 & 1.92169 \\ \mathrm{H} & 2.64291 & 0.00085 & -0.00000 \\ \mathrm{H} & 1.83769 & -1.11119 & -1.92169 \\ \mathrm{H} & -0.45652 & -1.43341 & -2.47748\end{array}$

\begin{tabular}{|c|c|c|c|c|}
\hline \multicolumn{2}{|c|}{ Bullvalene - TS } & \multicolumn{2}{|c|}{ Energy (B3LYP/6-311+G*): } & -387.051633 Hartree \\
\hline $\mathrm{C}$ & -0.66509 & 1.72125 & -0.00001 & \\
\hline C & -1.50470 & 0.47502 & -0.00000 & \\
\hline $\mathrm{C}$ & 0.66509 & 1.72125 & -0.00001 & \\
\hline
\end{tabular}




$\begin{array}{lrrr}\mathrm{C} & -1.24537 & -0.56524 & 1.05553 \\ \mathrm{C} & -1.24537 & -0.56524 & -1.05553 \\ \mathrm{C} & 0.00000 & -0.97492 & 1.51601 \\ \mathrm{C} & 1.24537 & -0.56523 & 1.05553 \\ \mathrm{C} & 1.50470 & 0.47503 & -0.00000 \\ \mathrm{C} & 1.24537 & -0.56524 & -1.05553 \\ \mathrm{C} & 0.00000 & -0.97493 & -1.51600 \\ \mathrm{H} & -1.19797 & 2.66896 & -0.00001 \\ \mathrm{H} & -2.56062 & 0.74480 & -0.00000 \\ \mathrm{H} & 1.19796 & 2.66897 & -0.00001 \\ \mathrm{H} & -2.12068 & -1.08213 & 1.43469 \\ \mathrm{H} & -2.12068 & -1.08213 & -1.43468 \\ \mathrm{H} & 0.00000 & -1.79475 & 2.23043 \\ \mathrm{H} & 2.12069 & -1.08212 & 1.43468 \\ \mathrm{H} & 2.56062 & 0.74481 & -0.00000 \\ \mathrm{H} & 2.12069 & -1.08213 & -1.43467 \\ \mathrm{H} & 0.00000 & -1.79476 & -2.23042\end{array}$

Semibullvalene - reactant Energy (B3LYP/6-311+G*): -309.641027 Hartree

$\begin{array}{lrrr}\mathrm{C} & 1.18176 & -1.11102 & -0.12586 \\ \mathrm{C} & 1.55463 & 0.05319 & -0.68312 \\ \mathrm{C} & 0.80655 & 1.18163 & -0.10242 \\ \mathrm{C} & 0.00000 & 0.64160 & 1.04183 \\ \mathrm{C} & -0.80655 & 1.18163 & -0.10242 \\ \mathrm{C} & -1.55463 & 0.05319 & -0.68312 \\ \mathrm{C} & -1.18176 & -1.11102 & -0.12586 \\ \mathrm{C} & 0.00000 & -0.89751 & 0.82037 \\ \mathrm{H} & -0.00000 & 1.08205 & 2.03326 \\ \mathrm{H} & 1.52067 & -2.09549 & -0.43010 \\ \mathrm{H} & 2.26438 & 0.15931 & -1.49632 \\ \mathrm{H} & 1.23746 & 2.17609 & -0.06979 \\ \mathrm{H} & -1.23746 & 2.17609 & -0.06979 \\ \mathrm{H} & -2.26438 & 0.15931 & -1.49632 \\ \mathrm{H} & -1.52067 & -2.09549 & -0.43010 \\ \mathrm{H} & 0.00000 & -1.51191 & 1.72276\end{array}$


Semibullvalene - product Energy (B3LYP/6-311+G*): $\quad-309.641027$ Hartree

$\begin{array}{llll}\mathrm{C} & -0.80494 & 1.18234 & -0.10270 \\ \mathrm{C} & -1.55450 & 0.05440 & -0.68330 \\ \mathrm{C} & -1.18294 & -1.11004 & -0.12582 \\ \mathrm{C} & -0.00085 & -0.89753 & 0.82031 \\ \mathrm{C} & 1.18079 & -1.11201 & -0.12585 \\ \mathrm{C} & 1.55471 & 0.05188 & -0.68304 \\ \mathrm{C} & 0.80748 & 1.18112 & -0.10234 \\ \mathrm{C} & 0.00046 & 0.64154 & 1.04186 \\ \mathrm{H} & -0.00130 & -1.51194 & 1.72270 \\ \mathrm{H} & -1.23556 & 2.17693 & -0.06900 \\ \mathrm{H} & -2.26419 & 0.16115 & -1.49649 \\ \mathrm{H} & -1.52317 & -2.09415 & -0.42989 \\ \mathrm{H} & 1.51896 & -2.09677 & -0.42999 \\ \mathrm{H} & 2.26491 & 0.15749 & -1.49594 \\ \mathrm{H} & 1.23937 & 2.17518 & -0.06947 \\ \mathrm{H} & -0.00025 & 1.08182 & 2.03337\end{array}$

Semibullvalene - TS Energy (B3LYP/6-311+G*): $\quad-309.633381$ Hartree

$\begin{array}{llll}\mathrm{C} & 1.06198 & -1.14348 & -0.09462 \\ \mathrm{C} & 1.60308 & 0.00001 & -0.66692 \\ \mathrm{C} & 1.06190 & 1.14349 & -0.09461 \\ \mathrm{C} & -0.00000 & 0.78410 & 0.90338 \\ \mathrm{C} & -1.06189 & 1.14349 & -0.09462 \\ \mathrm{C} & -1.60307 & 0.00001 & -0.66692 \\ \mathrm{C} & -1.06197 & -1.14347 & -0.09462 \\ \mathrm{C} & -0.00001 & -0.78414 & 0.90333 \\ \mathrm{H} & -0.00000 & 1.28831 & 1.87089 \\ \mathrm{H} & 1.33186 & -2.16426 & -0.32972 \\ \mathrm{H} & 2.30321 & 0.00003 & -1.49465 \\ \mathrm{H} & 1.33178 & 2.16428 & -0.32966 \\ \mathrm{H} & -1.33177 & 2.16428 & -0.32968 \\ \mathrm{H} & -2.30321 & 0.00003 & -1.49465 \\ \mathrm{H} & -1.33188 & -2.16425 & -0.32971 \\ \mathrm{H} & -0.00002 & -1.28840 & 1.87082\end{array}$

